\section{A construção política da ordem financeira}

Lourdes SOLA \& Laurence WHITEHEAD (eds.). Statecrafting monetary authority: democracy and financial order in Brazil. Oxford, Centre for Brazilian Studies, 2006. 392 páginas.

\section{Nicolás Cherny}

O propósito do livro compilado por Lourdes Sola e Laurence Whitehead é o de explicar o modo como se construiu uma autoridade monetária relativamente eficiente e legítima no Brasil. As contribuições do livro utilizam a estabilização produzida pelo plano real para mostrar que a autoridade monetária não sobrevém da importação de um modelo institucional capaz de funcionar em qualquer contexto (one fits all), mas de um conjunto de decisões de governo cujo conteúdo e timing são influenciados pela tensão entre as condições da democracia (os perfis do contexto institucional, as características e recursos dos atuantes envolvidos, as trajetórias dependentes, o calendário eleitoral etc.) e a pressão dos mercados financeiros específicos de cada contexto. Dentro da compilação podem ser distinguidos três tipos de artigos: a) os que descrevem os perfis históricos de duas instituições-chave para compreender o processo político de construção da autoridade monetária: o Fundo Monetário Internacional (FMI) e o próprio Banco Central do Brasil; b) um segundo conjunto de contribuições que são enfrentadas com o desafio de identificar as variáveis que explicam o processo específico de alteração nas características da autoridade monetária e, finalmente, c) os capítulos dedicados à relação entre a dinâmica das eleições e os mercados financeiros.

(a) Em "Recent modifications of the international financial system", Eduardo Kugelmas descreve as mudanças no FMI logo após a sucessão de crises financeiras ocorridas durante a segunda metade da década de 1990. Kugelmas sugere dois elementos que poderiam estar relacionados com essas alterações. Por um lado, o desempenho negativo dos países emergentes, objetos de acordos e monitoramento por parte do FMI (a crise da tequila, o sudeste asiático, Rússia, Brasil e Argentina), e, por outro, a modificação político-ideológica que a chegada de George W. Bush à presidência dos Estados Unidos fez supor. O primeiro desses elementos havia questionado aspectos relacionados às recomendações da política (os riscos da volatilidade de fluxos de capital, a rigidez dos regimes de tipos fixos de mudança e a aplicação das condicionalidades em qualquer contexto), o modo em que o FMI se relaciona com os governos (a intromissão no processo de política interna, o grau em que as missões podem se exceder em suas atribuições) e, por fim, a falta de transparência e o controle do próprio FMI, que conta com muito poder, porém carece de controle sobre a comunidade internacional.

Os efeitos do lentíssimo avanço na construção das instituições monetárias e financeiras no Brasil ao longo do século XX constituem o objetivo do trabalho de Maílson da Nóbrega e Gustavo Loyola ("The long and simoultaneous construction of fiscal and monetary institutions"). Eles defendem a idéia de que a raiz dos problemas da alta inflação dos anos de 1980 deve ser buscada na ausência de restrições fiscais às instituições monetárias: primeiro a concentração de atribuições monetárias e fiscais no Banco do Brasil e, depois, a presença de um departamento desenvolvedor no Banco Central haviam configurado um padrão de política "incestuoso". A capacidade de financiar expansões fiscais por meio da impressão de moeda dotava a autoridade monetária de uma enorme capacidade para armar coalizões com seus beneficiados (rurais, industriais, governadores, intendentes e membros do Congresso) para vetar mudanças em seu status quo. O regime militar primeiro e depois as tentativas de estabilização de processos inflacionários pelos governos democráticos permitiram a quebra dessa resistência: a execução do orçamento se transferiu do Banco do Brasil para o Ministério das Finanças, limitou o endividamento à aprovação do congresso e, com o plano real, consolidou-se a autonomia do Banco Central e melhorou seus níveis de transparência e eficiência operacional.

(b) Os capítulos dedicados a explicar o processo político da mudança na autoridade monetária brasileira são o centro da análise do livro. A contribuição conjunta de Sola e Kugelmas ("Crafting economic stabilization") descreve e explica o 
processo anterior à construção da autoridade monetária: o êxito da estabilização implantada pela gestão de Fernando Henrique Cardoso (FHC) como ministro da Fazenda. Os autores sugerem que os planos de estabilização enfrentam um duplo problema: o restabelecimento da confiança de agentes econômicos - cujo comportamento é estratégico em relação ao sistema de preços - de um modo que as expectativas inflacionárias sejam revertidas, ao mesmo tempo em que necessitam da colaboração dos atuantes políticos para modificar o regime monetário. Sola e Kugelmas apresentam uma explicação sobre a superação do padrão da alta inflação no Brasil, uma estabilização embasada em uma combinação de três elementos causais. Em primeiro lugar, a estratégia gradualista tornou as reformas compatíveis com os desafios de coordenação política que o presidente brasileiro enfrenta (em relação a outros países latino-americanos). $\mathrm{O}$ gradualismo havia dado uma margem a Fernando Henrique Cardoso para enfrentar duas restrições políticas: a fragmentação e baixa institucionalização dos partidos políticos brasileiros forçam o presidente a construir sua coalizão, uma vez estabelecido no governo; e a fluidez dos atuantes políticos e interesses organizados que, previsivelmente, resistiriam às mudanças no regime econômico. A eliminação da indexação representava um poderoso mecanismo de colaboração e abria espaço para um sinal de interrogação a respeito da capacidade do governo para encontrar apoio ao seu impulso reformista. $\mathrm{O}$ segundo elemento é a aprendizagem (cinco estabilizações heterodoxas falharam antes de 1992) e a utilização desse capital para a criação de inovações técnicas que conseguiram reverter o padrão explosivo da economia: o mais importante, a Unidade de Variação Real como instrumento de estabilização que evitaria as rigidezes de uma dolarização. A capacidade do governo de FHC de gerar e extrair novos recursos de poder das instituições vigentes statemanship - funciona como um terceiro elemento explicativo. A eficácia da estabilização reforçou o poder daqueles que a projetaram e executaram. As conseqüências dos longos danos da alta inflação não só converteram a estabilização de preços em uma prioridade para os governos, mas também em um ativo de enorme valor para a sociedade no Brasil (e na Argentina). De modo que a estabilização de preços outorgou ao presidente recursos de popularidade no governo para a armação de uma coalizão eleitoral. O resultado imediato do processo produz uma convergência entre credibilidade econômica e legitimidade política.

A explicação de Sola e Kugelmas é extremamente útil para se compreender o primeiro argumento que Sola e Marques desenvolveram ("Central banking, democratic governance and the quality of democracy"). A estabilidade de preços não é resultado da independência do Banco Central - e sim o que se pode conseguir sem ela - e no caso do Brasil representou uma janela de oportunidades que o governo aproveitou para conseguir uma autoridade monetária mais eficiente e accountable. Segundo os autores, as condições para a criação de um Banco Central autônomo são a conseqüência, e não a causa, da estabilidade de preços. O artigo de Kurt von Mettenheim ("From the economics of politics to the politics of monetary policy in Brazil") sustenta o mesmo argumento. Essa particular seqüência causal aponta para o fato de que as políticas ajustadas a contextos específicos e as trajetórias dependentes para a criação de novas capacidades ao Banco Central estão no cerne da criação da autoridade monetária. Isso não quer dizer que a independência monetária não incentive a estabilidade, mas é um resultado que se modifica segundo o contexto em que é aplicado: pode funcionar para economias desenvolvidas, porém não com mercados emergentes. Von Mettenheim faz uma conexão com as anomalias que tudo isso acarreta para as prescrições neoliberais. Em primeiro lugar, os avanços na construção da autoridade monetária provêm de políticas heterodoxas para se acabar com a inflação e, em segundo, após dez anos de estabilidade de preços, três dos maiores bancos se tornaram propriedade do governo.

A organização do relato feito com base na identificação dos atores relevantes, seus interesses, e em como as circunstâncias econômicas e políticas podem mudar sua posição de negociação relevante permite a Sola e a Marques construir uma explicação politológica consistente a respeito da mudança nas instituições monetárias. O segundo argumento que apresentam tem como ponto de partida a se- 
guinte pergunta: como uma autoridade monetária é construída em lugares onde existe uma história recorrente de hiperinflações? A resposta é que o principal recurso para construí-la foi obtido pela presidência de Fernando Henrique Cardoso, uma vez que a estabilização aumentou seu poder de negociação: o final da inflação debilitou os bancos estaduais que financiavam seus governos, tornando-os dependentes de um resgate financeiro diante do governo federal e das concomitantes eleições para a presidência, e, em 1994, o congresso e os estados dotaram FHC de maior poder sobre a legislatura (e, assim, sobre os governadores). A limitação que estabelecia a fixação cambiária para a emissão de moeda funcionou como uma restrição eficaz para evitar a monetização de déficits estaduais por parte dos bancos estaduais. Isso gerou uma dependência decisiva dos bancos estaduais em relação ao Banco Central, que o aparato econômico utilizou para redefinir as regras e os atores do sistema financeiro, reduzindo, assim, o risco moral. E o Banco Central consumou o que os autores chamam de uma "revolução silenciosa" do sistema financeiro, que consistiu em forçar os bancos que apresentavam problemas a realizar uma fusão com bancos sólidos, em evitar que os donos desses bancos pudessem manter a maioria das ações, em incentivar a entrada de bancos estrangeiros e em gerar um novo regulamento cujo objetivo é a minimização das operações de risco das instituições financeiras. Em suma, a estratégia de administração da crise concedeu ao governo uma margem de manobra e uma capacidade para tomar decisões politicamente onerosas sobre os atores de cuja colaboração, em outras circunstâncias e sob outras estratégias, não havia podido prescindir sem pôr em jogo sua própria sobrevivência. A redução do risco moral havia sido, segundo os autores, a razão pela qual o Brasil obteve uma rápida estabilização e recuperação do crescimento após a crise cambial do início de 1999.

Finalmente, Sola e Marques expõem que a experiência de controle parlamentar sobre o Banco Central - para verificar sua atuação na crise de 1999 - ilustra uma instituição cujos esforços de integrar o sistema financeiro brasileiro aos mercados financeiros internacionais a forçou a se ater a procedimentos mais transparentes e, portanto, mais capa- zes de prestar contas. A análise de Sola e Marques é convincente e reveladora a respeito do papel-chave que a política assume na consistência da política econômica e, em especial, nas estratégias das elites governamentais para produzir uma margem de manobra em que as restrições pareceram enclausurar a possibilidade de converter os roteiros em dilemas de política. Os mercados financeiros, entretanto, são o único ator cuja capacidade de dano o governo parecia ter menos possibilidade de moderar. Os autores afirmam que "o poder de fogo" do mercado deixa uma margem escassa aos governos e os condena a jogar o jogo da confiança. Cabe, então, a pergunta: que recursos os governos podem obter para limitar o poder de veto dos mercados financeiros internacionais? Há, pelo menos, quatro fontes de recursos. O primeiro surge da própria análise dos autores: o fortalecimento do sistema financeiro por meio da redução do risco moral. O segundo também já foi empregado pelos governos e surge da recuperação do instrumento de política cambial e monetária que pode habilitar estratégias contracíclicas e uma melhor absorção de shocks externos. A recuperação da solvência fiscal e, por conseguinte, a diminuição ao longo do tempo da exposição externa da dívida pode também reduzir a posição de vulnerabilidade dos governos. E, finalmente, alguma forma de controle de capitais se mostrou eficaz em ao menos minimizar os fluxos financeiros especulativos.

Como se explica que um governo latino-americano democrático tenha podido fazer convergirem a credibilidade econômica e a legitimidade política? Trata-se de um episódio meramente circunstancial, resultado de uma gestão de governo específica, ou se pode encontrar um padrão na política dos países em desenvolvimento que sugira uma mudança mais estrutural? O capítulo de Leslie Armijo - "Who's afraid of economic populism?" - mostra os pontos fracos da teoria do populismo econômico para explicar um resultado semelhante e trabalha uma hipótese alternativa baseada na teoria do eleitor médio. $O$ paradigma do populismo econômico sugere uma ampliação da participação política e proporciona voz política a grupos de pessoas que recebem baixos salários, cuja preferência política é o aumento do gasto estatal, 
uma maior expansão econômica e mais empregos, em vez de proteção contra a inflação para os ativos financeiros com os quais não contam. Dessa for$\mathrm{ma}$, as forças da democracia de massas gerariam instabilidade macroeconômica. A explicação de Armijo sugere que esse é somente um resultado circunstancial para a democracia brasileira. Um líder democrático racional não pode ficar muito distante do eleitor médio, cujas preferências, segundo Armijo, são viver em uma sociedade com uma moeda que mantenha seu valor e uma economia que cresça de forma sustentável. A partir dessa perspectiva, a democracia de massas é mais uma solução do que um problema para a sustentabilidade da política macroeconômica. A década de estabilização brasileira, a preferência dos menos favorecidos por candidatos que prometem condutas fiscais responsáveis e governos que promovem indistintamente esse tipo de política econômica mostram que não são as crises nem a insuflação da política econômica que acabam com o populismo econômico, e sim a evolução do eleitor médio. De forma similar a Sola e Marques, Armijo sugere que a estabilização de preços é eleitoralmente rentável, papel que o populismo econômico deixa de cumprir.

Finalmente, o capítulo de Mathew Taylor ("Courts, policy contestation, and the legitimation of economic reform under Cardoso") analisa o papel que o poder judiciário interpretou no processo de estabilização que teve início com o plano real. Taylor defende que os tribunais impuseram obstáculos a numerosas reformas, mas que proveram legitimidade a políticas socialmente controvertidas. Assim, o poder judiciário impôs custos à estratégia reformista do governo em curto prazo, mas ajudou a assegurar a sustentabilidade em longo prazo do programa de estabilização.

(c) Três capítulos abordam a relação entre incerteza eleitoral e crises financeiras. A concomitância em que são produzidos esses fenômenos e o fato de que tenham acontecido repetidamente em democracias com economias emergentes levaram Lawrence Whitehead a ensaiar um modelo de análise suscetível de se aplicar em diversos contextos. O objetivo do modelo é captar três problemas: o modo como os governos utilizam seu poder para administrar a crise financeira, o impacto que as res- trições externas exercem sobre a capacidade da democracia de produzir alternativas políticas e os resultados dos atores com diferentes temporalidades; enquanto os governos atuam nos tempos mais lentos da democracia, os mercados financeiros produzem decisões em segundos. O modelo que Whitehead apresenta é uma árvore de decisão desde um tempo considerável antes da eleição até quatro meses depois, que prescreve diferentes alternativas de decisão para os atores envolvidos e resultados dessa interação. A explicação parece funcionar muito bem com as experiências que combinam vulnerabilidade financeira (seja pelo compromisso com um tipo de câmbio fixo ou por necessidades de refinanciar a dívida em curto prazo) e a possível eleição de um candidato cuja reputação não é consistente com as expectativas do mercado. Os diferentes regimes cognitivos que informam os tempos dos atores e a reputação dos políticos são também elemento decisivo na análise que Javier Santiso realiza em "Wall Street and emerging democracies: financial markets and the Brazilian presidential elections". Santiso, em sua análise da eleição de 2002 no Brasil, mostra como a interação dos tempos antecipatórios do mercado em uma eleição na qual se suspeita que o provável vencedor (Lula) tenha o desejo de reestruturar a dívida - em um país com antecedentes de defaults -, apresenta uma intervenção crucial no que concerne ao comportamento dos candidatos e que pode acabar produzindo uma suspensão de pagamentos antes mesmo que a eleição seja consumada. De modo que, se os investidores se posicionam contra um país e a economia é fraca, é bastante possível que esse país não possa realizar a política de austeridade necessária para desmontar essas pressões. Ao contrário: se os sentimentos dos mercados se mantêm favoráveis, as mesmas condições de debilidade podem não ter conseqüências. A observação de Santiso do comportamento dos mercados financeiros é reveladora: a objeção que se pode fazer a essa explicação é, por um lado, que ela subestima as mudanças nos recursos e nas preferências dos atores domésticos e, por outro, que prescreve uma melhora institucional de um país do qual todas as alternativas de governos estejam dispostas a jogar o jogo da confiança. Uma menor vulnerabilidade da dívida e contas fiscais pode di- 
minuir o poder de veto dos mercados financeiros e ter menos repercussão nas preferências pelos candidatos.

A contribuição de Lourdes Sola - "Financial credibility, legitimacy and political discretion: the Lula da Silva government" - oferece uma explicação a respeito da relação entre eleições e mercados financeiros, que procura incluir os recursos e preferências dos atores domésticos. Sola mostra que a centralização das preferências por Lula durante a campanha funciona somente com o eleitorado, mas não com os mercados, que supunham que Lula não estaria disposto a pagar os custos do ajuste necessário para que a dívida fosse sustentável. Isso força o governo e Lula a mostrarem sinais - adesão dos candidatos ao acordo com o FMI, incorporação de um aliado de Lula ao governo uma vez iniciada a transição, depois um senador importante do governo preside o Banco Central -, procurando obter a credibilidade dos mercados. Uma vez no governo, Lula utiliza sua popularidade, a disciplina partidária e o controle dos movimentos sociais e sindicatos para reduzir a potencial inconsistência entre políticas que dêem credibilidade ao mercado, mas que frustrem seus eleitores. Sola mostra que, com essa estratégia, Lula reverte o déficit de credibilidade logo no primeiro ano, conseguindo legitimar sua tendência a continuar no jogo da confiança pela necessidade de corrigir o legado maligno que o governo anterior deixou para trás.

Em suma, as contribuições do livro mostram que as explicações embasadas em análises da teoria econômica são insuficientes para que os resultados das políticas econômicas e as modificações institucionais que produzem sejam compreendidos. A análise econômica deixa muitas coisas sem explicação. Este livro enfrenta esse desafio com ferramentas politológicas e se concentra nos aspectos políticos das políticas econômicas, além de aprimorar a compreensão dos resultados econômicos. Resultados que, por sua vez, mostram que a tensão entre a política nacional e a credibilidade financeira é inevitável para se compreenderem as decisões de governo enquanto este atravessa a política dos países que avançaram em reformas de liberalização econômica e cuja exposição externa, por vezes, os torna bastante vulneráveis.

\section{NICOLÁS CHERNY é doutorando em Ciência Política pela Universidade Complutense de Madri e pesquisador do Instituto de Investigaciones Gino Germani, da Universidade de Buenos Aires. E-mail: ncherny@iuperj.br}

Tradução de Arlete Dialetachi 